\title{
ADEQUANDO DADOS BIBLIOGRÁFICOS AO LINKED DATA: requisitos necessários, vantagens e desafios'
}

\author{
Fabiano Ferreira de Castro* \\ Ananda Fernanda de Jesus ${ }^{* *}$
}

RESUMO O Linked Data foi desenvolvido visando atender ao contexto tecnológico vigente e pode ser aplicado potencialmente ao domínio bibliográfico. Objetivou-se verificar a viabilidade e a relevância de se adequar os dados bibliográficos aos princípios do Linked Data. A coleta de dados baseou-se em uma metodologia de caráter qualiquantitativo, pautado na realização de uma Revisão Sistemática da Literatura. Os dados foram analisados à luz das seguintes categorias: enfoque dos documentos, requisitos necessários para a adequação de dados bibliográficos ao Linked Data, vantagens e desafios relacionados a essa adequação. Como resultados, identificaram-se o Resource Description Framework (RDF) e o Uniform Resource Identifier (URI) como requisitos necessários para prover a adequação de dados bibliográficos ao Linked Data. As principais vantagens identificadas foram a interoperabilidade de dados, melhores resultados de busca, maior visibilidade dos dados das bibliotecas no ambiente Web e promoção de descoberta acidental de recursos. Os principais desafios identificados foram a heterogeneidade dos dados disponibilizados na Web e a conversão dos dados descritos em formato MARC2I. Concluiu-se que os dados bibliográficos podem ser adequados ao Linked Data, porém, muitos desafios ainda precisam ser superados para permitir essa realidade.

Palavras-chave: Catálogo bibliográfico. Linked Data. Revisão Sistemática da Literatura.

\footnotetext{
* Doutor em Ciência da Informação pela Uniiversidade Estadual Julio de Mesquita Filho, Brasil. Professor do Departamento de Ciência da Informação da Universidade de São Carlos, Brasil. Docente permanente no Programa de Pós-Graduação em Ciência da Informação da Universidade de São Carlos, Brasil. Líder do Grupo de Pesquisa e Estudos em Representação do Conhecimento e Tecnologias da Informação e Comunicação. E-mail: fabianocastro.ufscar@gmail.com.

** Bacharelado em Biblioteconomia e Ciência da Informação pela Universidade de São Carlos, Brasil. Membro do Grupo de Pesquisa e Estudos em Representação do Conhecimento e Tecnologias da Informação e Comunicação. Bolsista da Fundação de Amparo à Pesquisa do Estado de São Paulo, Brasil. E-mal: anandafdj@gmail.com.
}

\section{INTRODUÇÃO'}

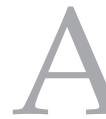

Internet, inicialmente de uso militar e acadêmico, se popularizou com o desenvolvimento da World Wide Web (Web) em 1989. Desde sua popularização até os dias atuais, as informações têm sido disponibilizadas nesse ambiente em diversos suportes, contextos

Artigo originado a partir da pesquisa intitulada "Dos catálogos bibliográficos ao movimento Linked Data: um estudo dos dados de controle de autoridade das Universidades Públicas Paulistas", financiada pelo $\mathrm{CNPq}$. e com diversas finalidades, criando um ambiente heterogêneo. Tendo como escopo a disponibilização de conteúdos informacionais em formato digital, não houve uma preocupação em garantir a recuperação desses conteúdos e/ ou ainda, a interoperabilidade entre as diversas fontes de informação nesse ambiente.

Para possibilitar o aproveitamento efetivo da informação disponibilizada no ambiente Web foi proposto o Linked Data que "[...] corresponde em princípios para promover a ligação de dados estruturados". (ARAKAKI, 2016, p. 17). 
As bibliotecas são tradicionalmente conhecidas pela consistência dos dados armazenados em seus catálogos, pautados na utilização de esquemas, formatos, protocolos e padrões de descrição. Elas adequaram-se ao ambiente Web, disponibilizando seus catálogos online, mas, ainda enfrentam o desafio de migrar os dados em formatos cujo objetivo final é apresentação a usuários humanos e que possibilitem o uso e reuso coletivo de informação no ambiente digital.

Apresentado o cenário tecnológico atual caracterizado pelas iniciativas de dados ligados, chegou-se a seguinte pergunta de pesquisa: Os dados bibliográficos podem caminhar para o movimento Linked Data?

Partiu-se da hipótese de que a adequação dos dados bibliográficos às práticas e às tecnologias do Linked Data pode contribuir para uma maior padronização dos dados bibliográficos, garantindo assim a unicidade das informações de forma a viabilizar a interoperabilidade no ambiente digital.

Este artigo tem por objetivo verificar a viabilidade e a relevância de se adequar os dados bibliográficos aos princípios do movimento Linked Data de forma a: (1) apresentar os conceitos relacionados aos dados bibliográficos; (2) identificar os principais requisitos para a adequação de dados de autoridade ao Linked Data; (3) apresentar os benefícios e os desafios relacionados à adequação dados bibliográficos ao Linked Data. Para atender esses objetivos baseouse na realização de uma Revisão Sistemática de Literatura (RS) que garantiu respaldar a criação de um arcabouço conceitual consistente acerca da temática.

\section{OS DADOS BIBLIOGRÁFICOS E O LINKED DATA}

Segundo Mey e Silveira (2009, p. 11) “[...] o catálogo é um dos instrumentos mais antigos das bibliotecas". Construídos inicialmente como simples listas alfabéticas, foram afetados pelo crescimento exponencial da produção de informação registrada e pela diversidade dos acervos advinda da criação de diferentes suportes para registro de informação. Essas mudanças fizeram com que o conceito de catálogo se tornasse muito mais complexo.

O catálogo pode ser definido como “[...] um canal de comunicação entre um usuário e um conjunto de recursos informacionais (acervo)" (ASSUMPÇÃO; SANTOS, 2012, p.1), e considerado como uma "[...] ferramenta para identificação de registros presentes em um acervo, por meio de descrição de elementos essenciais que permitam a identificação e localização da informação" (SANTARÉM SEGUNDO; SERRA, 2017, p. 169).

Para permitir a identificação, a localização e a recuperação da informação contida nos catálogos são realizadas as atividades de descrição bibliográfica e escolha dos pontos de acesso de autor e de título. É da atividade de descrição bibliográfica que resultam os dados bibliográficos.

As bibliotecas tradicionalmente buscaram adaptar-se aos ambientes informacionais nos quais estão inseridas, com "a disponibilização do Online Public Access Catalogue (OPAC) na Web, o alcance dos catálogos foi ampliado" (SANTARÉM SEGUNDO; SERRA, 2017, p. 173), porém, o crescente volume de informação registrada, gerado pelo advento do ambiente $W e b$ levantam questões sobre como representar de maneira consistente e em tempo hábil toda essa informação.

Uma das alternativas para lidar com esse cenário é o conjunto de práticas denominado Linked Data, que propõe a ligação de dados representados em um formato padrão, a partir da utilização de links semânticos, da utilização de ferramentas e de práticas propostas pelo movimento.

Os chamados princípios do Linked Data são compostos por quatro recomendações básicas, como aponta Berners-Lee (2006):

1 - Uso de Uniform Resource Identifier (URIs) - Os URIs são identificadores que servem para representar documentos, locais, endereços da $\mathrm{Web}$, figuras ou até mesmo pessoas. A diferença entre os Uniform Resource Locator (URLs), identificadores tradicionais da Web 2.0, e URIs consiste no fato de que "[...] ao contrário dos URLs [...] os URIs são identificadores únicos no espaço de um dado servidor, resultando, portanto, em identificadores únicos no espaço da Web" (MARCONDES, 2012, p. 179), impedindo que o caminho para a informação se perca com o tempo. 
2. Uso de HTTP URIs - Para permitir que o URI que representa um recurso possa ser acessado em um navegador e ocorra a "transferência dos dados entre algum computador-servidor conectado à Internet $\mathrm{e}$ ao computador-cliente que solicitou o recurso" (RAMALHO, 2006, p. 33) é necessário a utilização de um protocolo, sendo o mais comum deles o HTTP.

3. Uso do Resource Description Framework (RDF) - O modelo foi proposto em 1999 com o objetivo de promover a interoperabilidade e a padronização dos recursos hospedados na Web. As declarações em $R D F$ são compostas por um "conjunto de triplas recurso-propriedade-valor, usadas para descrever recursos, onde um recurso é qualquer «coisa» do mundo real identificada por um endereço Web". (FREITAS JUNIOR; JACYNTO, 2016, p. 2).

4. Inclusão de links para outros URIs, - É essa recomendação que dá nome ao movimento, a criação de links entre URIs é o que possibilitar a descoberta acidental de conteúdos.

Embora nenhuma dessas recomendações seja indispensável, não adotar uma delas, segundo Berners-Lee (2006), limitaria as formas como os dados podem ser utilizados e reutilizados no ambiente $W e b$.

\section{METODOLOGIA}

Essa pesquisa possui caráter exploratório e descritivo, tendo como finalidade subsidiar a discussão e desenvolver um corpus teórico entre a iniciativa Linked Data e os dados bibliográficos. Do ponto de vista de sua natureza e abordagem de tratamento do seu objeto e objetivos caracteriza-se como uma pesquisa mista com abordagens quantitativa e qualitativa.

Para possibilitar a construção de um referencial teórico do tema abordado optouse pela realização da Revisão Sistemática da
Literatura (RS) como método de coleta de dados. Uma Revisão Sistemática da Literatura é um meio de identificar, avaliar e interpretar todas as pesquisas disponíveis relevantes para uma determinada questão de pesquisa [...] (KITCHENHAM, 2004, p.1, tradução nossa). A RS consiste em uma revisão bibliográfica acrescida de critérios e etapas rigorosas que garantem a qualidade e a representatividade dos documentos obtidos, [...] são desenhadas para serem metódicas, explícitas e passíveis de reprodução. (MANCINI; SAMPAIO, 2007, p. 83). Ser passível de reprodução é uma das principais características de uma RS, principalmente por permitir que os resultados localizados possam ser facilmente auditados e que a pesquisa possa ser continuada do ponto em que foi interrompida.

A condução da RS foi dividida em três etapas principais, a saber: (1) Planejamento, incluindo a análise exploratória e o preenchimento do protocolo de busca; (2) Condução, que consiste na busca em bases de dados e portais de periódicos definidas no protocolo de busca, bem como na aplicação dos critérios de inclusão e exclusão; (3) Extração de dados, onde foi realizada uma leitura mais criteriosa dos documentos selecionados, cujos dados de interesse foram extraídos e sistematizados. Para auxiliar no processo de realização da RS utilizou-se a ferramenta denominada StArt (State of the Art through Systematic Review), desenvolvida pelo Laboratório de Pesquisa em Engenharia de Software (LAPES), do Departamento de Ciência da Computação, da Universidade Federal de São Carlos (UFSCar).

$\mathrm{Na}$ etapa de planejamento preencheu-se um protocolo contendo 18 campos utilizados para registrar os processos de busca, apresentado no quadro 1. 
Quadro 1: Protocolo de busca da Revisão Sistemática.

\begin{tabular}{|c|c|}
\hline \multicolumn{2}{|c|}{ Protocolo da Revisão Sistemática: Linked Data aplicado a dados bibliográficos. } \\
\hline Objectives: & $\begin{array}{l}\text { Verificar a viabilidade e a relevância de se adequar os dados bibliográficos aos } \\
\text { princípios do movimento Linked Data a partir de uma análise das vantagens e dos } \\
\text { desafios relacionados a essa adequação. }\end{array}$ \\
\hline Main Question: & Os dados bibliográficos podem caminhar para o movimento Linked Data? \\
\hline Intervention: & Estudos conceituais ou práticos da adequação de dados bibliográficos ao Linked Data. \\
\hline Control: & $\begin{array}{l}\text { Análise exploratória do tema, considerando artigos, teses e dissertações publicados } \\
\text { sobre a temática. }\end{array}$ \\
\hline Population: & $\begin{array}{l}\text { Resultados de projetos de adequação de dados de autoridade ao Linked Data, } \\
\text { especificamente as vantagens, desafios e requisitos relacionados a esses projetos, que } \\
\text { permitam desenvolver um corpus teórico entre a iniciativa Linked Data e os dados } \\
\text { bibliográficos. }\end{array}$ \\
\hline Results: & $\begin{array}{l}\text { Como resultados esperados deseja-se a construção de uma base teórico-metodológica } \\
\text { mais consolidada a cerca da relevância e da pertinência de promover a adequação dos } \\
\text { dados bibliográficos ao Linked Data. }\end{array}$ \\
\hline Application: & Profissionais da Ciência da Informação que trabalhem com catalogação descritiva. \\
\hline Keywords: & $\begin{array}{l}\text { ("Linked Data") AND ("Bibliographic Catalog" OR "Bibliographic Data" OR "Bibliographic } \\
\text { Control" OR "Cataloguing" "Catalog") }\end{array}$ \\
\hline Source Selection Criteria: & $\begin{array}{l}\text { Artigos científicos publicados em periódicos da área de Biblioteconomia e Ciência da } \\
\text { Informação. }\end{array}$ \\
\hline Studies Languages: & Inglês, Português e Espanhol; \\
\hline Source Search Methods: & $\begin{array}{l}\text { Leitura do título e resumo dos documentos, aplicação dos critérios de inclusão e exclusão, } \\
\text { leitura da introdução e conclusão ou ainda do documento completo nos casos em que as } \\
\text { análises anteriores se mostrarem inconclusivas para a seleção. }\end{array}$ \\
\hline Source Engine ${ }^{1}$ : & $\begin{array}{l}\text { Web of Science; Library and Information Science Abstracts (LISA); Information Science \& } \\
\text { Technology Abstracts (LISTA); Library, Information Science \& Technology Abstracts with full } \\
\text { text (ISTA) e Base de dados de Periódicos em Ciência da Informação (BRAPCI). }\end{array}$ \\
\hline $\begin{array}{l}\text { Studies inclusion and } \\
\text { exclusion criterias: }\end{array}$ & $\begin{array}{l}\text { (I) Aborda dados bibliográficos relacionados ao contexto do Linked Data; (I) Apresentar } \\
\text { resultados de projetos de adaptação de dados bibliográficos ao Linked Data. (E) O } \\
\text { documento não estar disponível ou não pode ser facilmente localizado na íntegra no } \\
\text { ambiente Web. (E) Não estar nos idiomas estabelecidos para a pesquisa (E) Não ter por } \\
\text { enfoque ou abordar amplamente a relação de Linked Data a dados bibliográficos. }\end{array}$ \\
\hline Studies types definition: & Artigos de periódicos, sem restrição do período de publicação. \\
\hline Initial studies selection: & Não se aplica ao estudo. \\
\hline $\begin{array}{l}\text { Studies quality } \\
\text { evaluation: }\end{array}$ & $\begin{array}{l}\text { A avaliação da qualidade dos documentos será feita a partir da análise da metodologia } \\
\text { dos estudos aceitos. }\end{array}$ \\
\hline $\begin{array}{l}\text { Information Extraction } \\
\text { Fields: }\end{array}$ & $\begin{array}{l}\text { Enfoque dos documentos. Requisitos necessários para adequar dados bibliográficos ao } \\
\text { Linked Data. Vantagens de adequar os dados bibliográficos ao Linked Data. Desafios de } \\
\text { adequar os dados bibliográficos ao Linked Data. }\end{array}$ \\
\hline Results Summarization: & $\begin{array}{l}\text { Após extração de dados, realizada seguindo o roteiro proposto no campo "Information } \\
\text { Extraction Fields", os dados foram agrupados em quadros de acordo com a categoria de } \\
\text { análise, os resultados semelhantes foram agrupados permitindo a realização de uma } \\
\text { análise quantitativa e também a elaboração de inferências que permitiram responder } \\
\text { a pergunta de pesquisa. }\end{array}$ \\
\hline
\end{tabular}

Fonte: Autores $(2017)^{2}$

2 A escolha das bases de dados se justifica por se tratarem das principais fontes em Ciência da Informação e Biblioteconomia, com acesso por meio do vínculo institucional via portal de periódicos CAPES. 
$\mathrm{Na}$ etapa de condução os resultados obtidos através de busca nas bases de dados foram exportados em um dos formatos legíveis pelo StArt e inseridos no software; as referências duplicadas foram identificadas, e os documentos foram selecionados a partir de uma leitura da introdução e das conclusões dos documentos, ou ainda do texto completo, caso se mostrasse necessária para a seleção

Para possibilitar a realização da etapa de extração foi necessário definir as categorias de análise, que identificam quais as informações que serão buscadas, registradas e sistematizadas em cada um dos documentos recuperados. Para essa pesquisa foram definidas quatro categorias de análise conforme figura 1:

Figura 1: Categorias de análise da Revisão Sistemática de Literatura

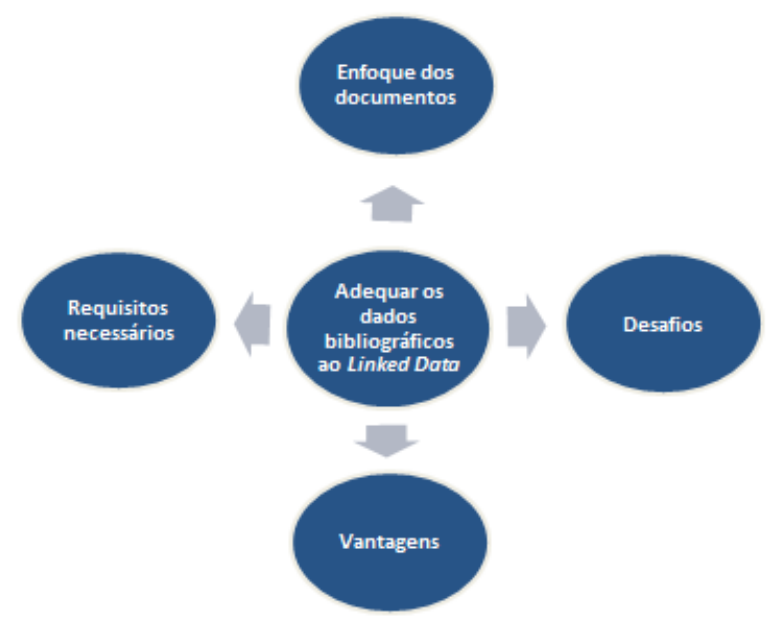

Fonte: Autores (2017)

Os dados das categorias "Desafios" e "Vantagens" de se adequar os dados bibliográficos ao Linked Data foram sistematizados em tabelas individuais contendo o título, o autor e o ano de publicação dos documentos e as informações localizadas. Os dados das categorias "Requisitos necessários" e "Enfoque dos documentos" foram tabulados e analisados numericamente.

\section{DOS RESULTADOS: RELATÓRIO DA REVISÃO SISTEMÁTICA}

Durante o processo de busca nas bases de dados selecionadas foram localizados 1.376 documentos. Na primeira etapa, denominada selection foram identificados $764 \quad(56 \%)$ como sendo duplicados, 434 (31\%) foram identificados como passíveis de exclusão, e 178 (13\%) foram aceitos de acordo com os critérios estabelecidos, a partir da leitura do resumo, título e das palavras-chave dos artigos.

A etapa seguinte, denominada com "extraction" no StArt, consistiu na análise e refinamento dos 178 documentos aceitos na etapa anterior, realizada a partir da leitura da introdução e das conclusões dos documentos ou ainda do texto completo, caso essa leitura se mostrasse necessária para a seleção. Ao final foram aceitos 56 documentos, todos artigos de periódicos, conforme a figura 2:

Figura 2: Resultado da etapa "Extraction" no software StArt.

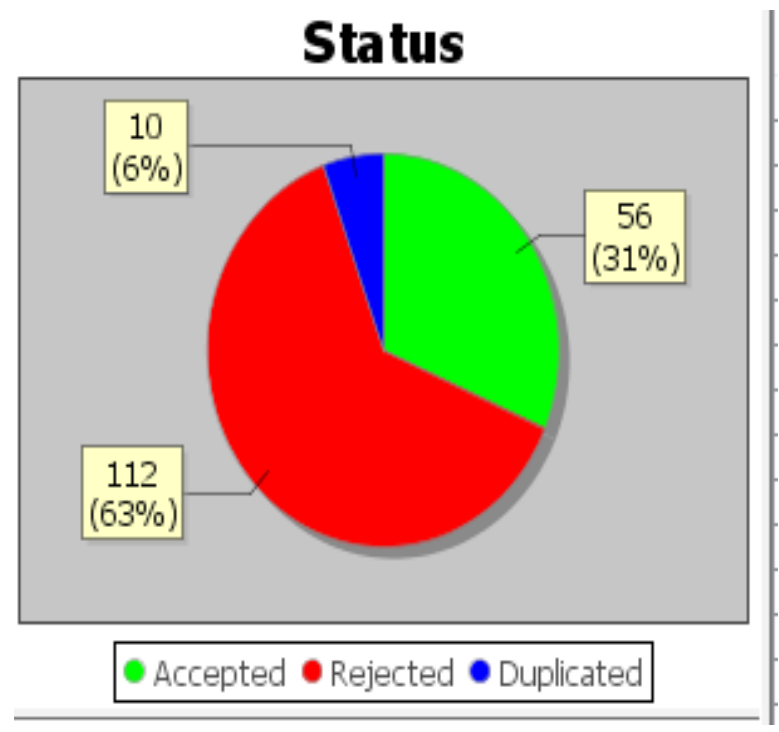

Fonte: Autores (2017).

Esse alto índice de rejeições (63\%) ocorre pelo fato de que a estratégia de busca foi construída de forma a recuperar todos os documentos que abordem a temática, assim sendo recuperou-se uma maior quantidade de ruídos.

Os documentos selecionados tratam da adequação de dados de autoridade e dados bibliográficos aos princípios do Linked Data como tema geral. Nessa etapa também foram extraídas as informações definidas nas categorias de análise apresentadas na figura 1 . 


\section{I Enfoques dos documentos obtidos}

Durante a etapa de extração de dados da Revisão Sistemática foram identificados 10 temas como enfoques dos documentos aceitos, apresentados no quadro 2:

Quadro 2: Enfoques dos documentos recuperados na Revisão Sistemática.

\begin{tabular}{|l|c|}
\hline \multicolumn{1}{|c|}{ Enfoque } & $\mathbf{N}^{\circ}$ de ocorrências \\
\hline Apresentar um projeto de adequação dos dados bibliográficos ao Linked Data & 15 \\
\hline Discutir a relação entre Linked Data e dados de autoridade & 11 \\
\hline Discutir o processo de conversão de dados bibliográficos ao Linked Data & 10 \\
\hline Discutir a relação entre Linked Data e dados bibliográficos & 6 \\
\hline Discutir a relação entre Linked Data e publicações seriadas & 4 \\
\hline Discutir a relação entre Linked Data einteroperabilidade de dados bibliográficos & 3 \\
\hline $\begin{array}{l}\text { Discutir os desafios do processo de adequação de dados bibliográficos ao } \\
\text { Linked Data }\end{array}$ & 1 \\
\hline Discutir a relação entre Linked Data e o Controle Bibliográfico Universal & 1 \\
\hline $\begin{array}{l}\text { Discutir a relação entre Linked Data e um formato para descrição de recursos } \\
\text { bibliográficos }\end{array}$ & 1 \\
\hline
\end{tabular}

Fonte: Autores (2017)

Dentre as temáticas abordadas nos estudos destaca-se como tema central "Apresentar um projeto de adequação de dados de uma biblioteca ao Linked Data", tendo sido abordado por 15 documentos. Esse fato demonstra uma forte tendência de aplicação prática nessa temática, o objetivo central dos documentos foi apresentar o trabalho realizado por uma biblioteca para adotar as práticas e os princípios do Linked Data, essas pesquisas oferecem suporte para iniciativas futuras por registrarem as experiências práticas de bibliotecas com a adequação de seus dados bibliográficos ao movimento.

O segundo destaque dentre as temáticas foi "Discutir a relação entre Linked Data e dados de autoridade" demonstrando uma preocupação com os dados de autoridade das bibliotecas, sendo o enfoque de 11 documentos. Um único registro de autoridade pode estar associado a milhares de outros registros, isso considerando apenas o ambiente dos catálogos, quando estimados os registros presentes no ambiente Web, esse número se torna praticamente imensurável, esse alto potencial de ligações torna os dados de autoridade uma das chaves para a conversão dos dados bibliográficos ao Linked Data.

Outro destaque foi "discutir o processo de conversão dos dados bibliográficos ao Linked Data", abordado por 10 documentos, demonstrando uma forte preocupação com o reaproveitamento das grandes coleções de dados bibliográficos das bibliotecas. Essa preocupação também se confirma na análise dos principais desafios à adequação dos dados bibliográficos ao Linked Data. Observa-se também, entre os documentos recuperados, uma ausência de uma tentativa conjunta para construir e adequar os esquemas, os padrões, os códigos e os formatos do domínio bibliográfico para serem utilizados no processo de construção de dados bibliográficos semânticos e interligados.

\subsection{Requisitos necessários para a adequação de dados bibliográficos ao linked data}

Dos 56 artigos estudados, 48 indicaram um ou mais requisitos necessários para a 
publicação de dados bibliográficos de acordo com os princípios do Linked Data. Desses 48 documentos, 42 citaram o RDF como um requisito necessário para a publicação, 35 citaram URIs e/ ou URIs HTTPS como requisitos necessários para a publicação, 18 citaram a necessidade de reutilizar ontologias existentes e criar ontologias/ vocabulários próprios para possibilitar a descrição de recursos bibliográficos em Linked Data. Em apenas 4 dos documentos foi mencionada a necessidade do uso de um padrão para descrição de conteúdos, sendo que o único padrão utilizado como exemplo foi o $R D A ; 2$ documentos mencionaram o uso dos requisitos funcionais FRBR como um possível facilitador do processo de adequação.

Percebe-se uma lacuna no período de dez anos analisado (2006 a 2016) de estudos relacionando diretamente à publicação de dados bibliográficos semânticos e interligados com a utilização de padrões de descrição, que formam a base para garantir a consistência dos dados gerados pelas bibliotecas; isso se confirma no estudo dos enfoques dos documentos, onde nenhum estudo específico sobre o uso de padrões de descrição e o Linked Data foi recuperado. Outra lacuna identificada foi a falta de estudos sobre softwares gerenciadores de bibliotecas e o Linked Data, nenhum estudo tratando especificamente do assunto foi localizado.

É um destaque entre os estudos recuperados, que para publicar dados bibliográficos de acordo com o Linked Data, os requisitos fundamentais são o $R D F$ e o uso de URIs/URIs HTTP para identificar as entidades relacionadas ao item descrito e ao próprio item.

\subsection{Vantagens de adequar os dados bibliográficos ao linked data}

As vantagens de se adequar os dados bibliográficos ao Linked Data foram estudadas com o objetivo de verificar a relevância desse processo. Dos 56 recuperados na RS, 29 citaram uma ou mais vantagens de aplicar as recomendações do Linked Data aos dados bibliográficos, conforme apresentadas no quadro 3.

Quadro 3: Vantagens da utilização de Linked Data para a publicação de dados bibliográficos.

\begin{tabular}{|c|c|c|}
\hline Autor (es) & Título & Vantagens mencionadas \\
\hline Long (2016) & $\begin{array}{l}\text { Disambiguating the Departed: } \\
\text { Using the Genealogist's Tools } \\
\text { to Uniquely Identify the Long } \\
\text { Dead and Little Known. }\end{array}$ & $\begin{array}{l}\text { - Garantir a unicidade dos dados de } \\
\text { autoridade de pessoas pouco conhecidas } \\
\text { ou falecidas há muito tempo. }\end{array}$ \\
\hline $\begin{array}{l}\text { Leiva-Mederos et al. } \\
\text { (2013) }\end{array}$ & $\begin{array}{l}\text { AUTHORIS: a tool for authority } \\
\text { control in the semantic web. }\end{array}$ & $\begin{array}{l}\text { - Reutilização dos dados de autoridade. } \\
\text { - Interoperabilidade entre dados de } \\
\text { bibliotecas e dados de organizações } \\
\text { privadas como editoras e livrarias. }\end{array}$ \\
\hline $\begin{array}{l}\text { Agenjo, Hernández e } \\
\text { Viedma (2012) }\end{array}$ & $\begin{array}{l}\text { Data Aggregation and } \\
\text { Dissemination of Authority } \\
\text { Records through Linked Open } \\
\text { Data in a European Context. }\end{array}$ & $\begin{array}{l}\text { - Maior granularidade na representação } \\
\text { multilíngue. } \\
\text { - Transpõe barreiras linguísticas. }\end{array}$ \\
\hline Han (2016) & 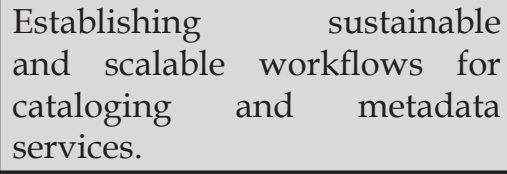 & $\begin{array}{l}\text { - Interoperabilidade e cooperação entre } \\
\text { diversas instituições } \\
\text { - Agilizar o processo de tratamento de } \\
\text { novos itens. }\end{array}$ \\
\hline Xu et al. (2016) & $\begin{array}{l}\text { Initial BIBFRAME } 2.0 \text { Modeling } \\
\text { for the Library Information } \\
\text { Spotlight "Opera Planet". }\end{array}$ & $\begin{array}{l}\text { - Ligação entre os diversos suportes e } \\
\text { manifestações de uma obra }\end{array}$ \\
\hline
\end{tabular}




\begin{tabular}{|c|c|c|}
\hline Bidney e Clair (2013) & $\begin{array}{l}\text { Harnessing the } \quad \text { Geospatial } \\
\text { Semantic Web: Toward } \\
\text { Place-Based } \\
\text { Organization and Access. }\end{array}$ & $\begin{array}{l}\text { - Maior acesso e visibilidade de dados. } \\
\text { - Diversidade de refinamento de busca } \\
\text { além do tradicional (exemplo: onde um } \\
\text { item foi escrito, onde uma história ocorre } \\
\text { ou onde um autor viveu). }\end{array}$ \\
\hline Laurence (2013) & $\begin{array}{l}\text { Linked Data and the Library of } \\
\text { Congress. }\end{array}$ & $\begin{array}{l}\text { - Redução do tempo empregado para a } \\
\text { catalogação de novos itens. } \\
\text { - Excluir a necessidade de manter um } \\
\text { banco de dados individual, possibilidade } \\
\text { de manter bancos de dados coletivos. } \\
\text { - Possibilidade de descoberta "acidental" } \\
\text { de informação. } \\
\text { - Fazer com que os dados dos catálogos } \\
\text { apareçam em buscas realizadas na Web. } \\
\text { - Resultados de busca mais significativos. }\end{array}$ \\
\hline Talleras (2013) & $\begin{array}{l}\text { From Many Records to } \\
\text { One Graph: Heterogeneity } \\
\text { Conflicts in the Linked data } \\
\text { Restructuring Cycle. }\end{array}$ & - Interoperabilidade de dados. \\
\hline $\begin{array}{l}\text { Richard e Thompsone } \\
(2013)\end{array}$ & $\begin{array}{l}\text { Moving Our Data to the } \\
\text { Semantic Web: Leveraging a } \\
\text { Content Management System } \\
\text { to Create the Linked Open } \\
\text { Library. }\end{array}$ & $\begin{array}{l}\text { - Conjunto de dados mais rico e mais } \\
\text { reutilizável. }\end{array}$ \\
\hline $\begin{array}{l}\text { Kumar, Ujjal e Utpal } \\
\text { (2017) }\end{array}$ & $\begin{array}{l}\text { Exposing MARC } 21 \text { Format for } \\
\text { Bibliographic Data As Linked } \\
\text { Data With Provenance. }\end{array}$ & $\begin{array}{l}\text { - Interoperabilidade com dados de outras } \\
\text { fontes. }\end{array}$ \\
\hline Perkins e Yoose (2013) & $\begin{array}{l}\text { The Linked Open Data } \\
\text { Landscape in Libraries and } \\
\text { Beyond. }\end{array}$ & $\begin{array}{l}\text { - Facilitar a interoperabilidade entre } \\
\text { instituições do setor cultural. } \\
\text { - Representação mais granular de } \\
\text { publicações seriadas. }\end{array}$ \\
\hline Mebmer (2013) & $\begin{array}{l}\text { Linking Library Metadata } \\
\text { to the Web: The German } \\
\text { Experiences. }\end{array}$ & - Interoperabilidade de dados. \\
\hline Solodovnik (2013) & $\begin{array}{l}\text { Bibliographic Data Towards } \\
\text { the Semantic Web: A Review } \\
\text { of Key Issues and Recent } \\
\text { Experiences }\end{array}$ & $\begin{array}{l}\text { - Permitir que a abundância de ligações } \\
\text { potenciais de um único objeto seja } \\
\text { aproveitada. } \\
\text { - Facilitar a localização de dados de } \\
\text { difícil acesso. }\end{array}$ \\
\hline $\begin{array}{l}\text { Goddard e Seeman } \\
(2014)\end{array}$ & $\begin{array}{l}\text { Preparing the Way: Creating } \\
\text { Future Compatible Cataloging } \\
\text { Data in a Transitional } \\
\text { Environment. }\end{array}$ & $\begin{array}{l}\text { - Permitir a utilização mais ampla dos } \\
\text { dados de autoridade. } \\
\text { - Permitir mapear a relação entre pessoas, } \\
\text { ideias, organizações, conceitos etc. } \\
\text { - A reutilizaça de recursos externos } \\
\text { permite que a biblioteca se concentre na } \\
\text { descrição mais rica de recursos locais. }\end{array}$ \\
\hline
\end{tabular}




\begin{tabular}{|c|c|c|}
\hline $\begin{array}{l}\text { Borie e Van Ballegooie } \\
\text { e (2014) }\end{array}$ & $\begin{array}{l}\text { From Record-Bound to } \\
\text { Boundless: FRBR, Linked } \\
\text { Data, and New Possibilities for } \\
\text { Serials Cataloging. }\end{array}$ & $\begin{array}{l}\text { - Melhorar o sistema de busca, gerando } \\
\text { resultados mais relevantes. } \\
\text { - Interoperabilidade entre os } \\
\text { dados das bibliotecas e dados } \\
\text { das editoras e casas publicadoras. } \\
\text { - Maior granularidade na representação } \\
\text { de publicações seriadas ao permitir a } \\
\text { identificação. } \\
\text { - Diferenciar o jornal do artigo. } \\
\text { - Diferenciar os títulos anteriores e atuais } \\
\text { de periódicos. } \\
\text { - Múltiplas versões passariam ser } \\
\text { tratadas como instâncias e eliminariam a } \\
\text { necessidade de múltiplos registros. } \\
\text { - Permitir ligar as obras a traduções, } \\
\text { interpretações, estudos e ensaios } \\
\text { facilitando o trabalho de pesquisa. } \\
\text { - Relacionar os dados de um trabalho } \\
\text { com os de seu contexto histórico. }\end{array}$ \\
\hline Fallgren et al. (2014) & $\begin{array}{l}\text { The Missing Link - The } \\
\text { Evolving Current State of } \\
\text { Linked Data for Serials }\end{array}$ & $\begin{array}{l}\text { - Interoperabilidade com outros sistemas } \\
\text { fora da comunidade de bibliotecas. } \\
\text { - Descoberta não intencional de } \\
\text { informação. } \\
\text { - Tornar os recursos das bibliotecas mais } \\
\text { localizáveis no ambiente } W e b .\end{array}$ \\
\hline Seppälä (2014) & \begin{tabular}{|l|} 
Toward multidimensional \\
descriptions.
\end{tabular} & $\begin{array}{l}\text { - Expandir as possibilidades e a } \\
\text { qualidade dos resultados de buscas. }\end{array}$ \\
\hline Wenz (2013) & $\begin{array}{l}\text { Linked Open Data for New } \\
\text { Library Services: The Example } \\
\text { of data.bnf.fr. }\end{array}$ & $\begin{array}{l}\text { - Aproximar coleções que antes só } \\
\text { seriam acessadas por um público muito } \\
\text { específico do público geral. } \\
\text { - Possibilitar relacionar todas as edições } \\
\text { de um livro (cria novas possibilidades de } \\
\text { resultados de busca). }\end{array}$ \\
\hline Martini (2013) & $\begin{array}{l}\text { Bibliographic Standards and } \\
\text { Linked Data. Towards a } \\
\text { Collaboration between Cultural } \\
\text { and Commercial Sectors. }\end{array}$ & $\begin{array}{l}\text { - Permitir a interoperabilidade de dados } \\
\text { entre o setor cultural e comercial. }\end{array}$ \\
\hline Alemu et al. (2012) & $\begin{array}{l}\text { Linked Data for libraries: } \\
\text { Benefits of a conceptual shift } \\
\text { from library-specific record } \\
\text { structures to RDF-based data } \\
\text { models. }\end{array}$ & $\begin{array}{l}\text { - Tornar a informação facilmente } \\
\text { acessível. } \\
\text { - Facilitar a reutilização, a integração } \\
\text { e o compartilhamento de dados com } \\
\text { fornecedores externos de informação. } \\
\text { - Facilitar a descoberta acidental de } \\
\text { recursos. } \\
\text { - Eliminariam a duplicação desnecessária } \\
\text { de dados já disponíveis em outras fontes }\end{array}$ \\
\hline
\end{tabular}




\begin{tabular}{|c|c|c|}
\hline Coyle (2011) & $\begin{array}{l}\text { Designing Data for Use: From } \\
\text { Alphabetic Order to Linked } \\
\text { Data. }\end{array}$ & $\begin{array}{l}\text { - Facilitar a reutilização das informações } \\
\text { contidas nos metadados. } \\
\text { - Permitir a interoperabilidade de dados. }\end{array}$ \\
\hline $\begin{array}{l}\text { Clayphan, Haslhofer e } \\
\text { Isaac (2012) }\end{array}$ & $\begin{array}{l}\text { EUROPEANA: Moving to } \\
\text { Linked Open Data. }\end{array}$ & $\begin{array}{l}\text { - Maior visibilidade dos dados e dos } \\
\text { acervos das bibliotecas no ambiente Web. }\end{array}$ \\
\hline $\begin{array}{l}\text { Godby e Smith- } \\
\text { Yoshimura (2016) }\end{array}$ & $\begin{array}{l}\text { From Records to Things: } \\
\text { Managing the Transition from } \\
\text { Legacy Library Metadata to } \\
\text { Linked Data. }\end{array}$ & $\begin{array}{l}\text { - As barreiras de linguagem podem ser } \\
\text { transpostas com mais facilidade } \\
\text { - Mais precisão e abrangência nos } \\
\text { resultados das buscas. }\end{array}$ \\
\hline Johnson (2013) & $\begin{array}{l}\text { Indexing Linked Bibliographic } \\
\text { Data with JSON-LD, BibJSON } \\
\text { and Elasticsearch. }\end{array}$ & $\begin{array}{l}\text { - Compartilhar e reutilizar dados em } \\
\text { escala global. } \\
\text { - Interoperabilidade de dados entre } \\
\text { diversas fontes. }\end{array}$ \\
\hline Carragáin et al (2015) & $\begin{array}{l}\text { Linked data authority records } \\
\text { for Irish place names. }\end{array}$ & $\begin{array}{l}\text { - Aprimorar os resultados de busca. } \\
\text { - Possibilitar a descoberta acidental de } \\
\text { recursos } \\
\text { Agregar valor e granularidade de } \\
\text { descrição às representações com a adição } \\
\text { de dados de fontes externas. }\end{array}$ \\
\hline Miller e Ogbuji (2015) & $\begin{array}{l}\text { Linked Data Design for the } \\
\text { Visible Library. }\end{array}$ & $\begin{array}{l}\text { - Maior visibilidade para os dados das } \\
\text { bibliotecas e para as suas coleções. }\end{array}$ \\
\hline Gonzales (2014) & $\begin{array}{l}\text { Linking Libraries to the Web: } \\
\text { Linked Data and the Future of } \\
\text { the Bibliographic Record. }\end{array}$ & $\begin{array}{l}\text { - Maior visibilidade aos dados das } \\
\text { bibliotecas. } \\
\text { - Dados ricos e reutilizáveis. } \\
\text { - Permitir a descoberta acidental de } \\
\text { recursos. }\end{array}$ \\
\hline $\begin{array}{l}\text { Santos Neto et al. } \\
(2013)\end{array}$ & $\begin{array}{l}\text { Tecnologias de dados abertos } \\
\text { para interligar bibliotecas, } \\
\text { arquivos e museus: um caso } \\
\text { machadiano. }\end{array}$ & - Interoperabilidade no setor cultural. \\
\hline Catarino e Souza (2012) & $\begin{array}{l}\text { A representação descritiva no } \\
\text { contexto da web semântica. }\end{array}$ & $\begin{array}{l}\text { - Enriquecimento dos resultados de } \\
\text { busca. } \\
\text { - Descoberta acidental de recursos. }\end{array}$ \\
\hline
\end{tabular}

A interoperabilidade de dados foi a vantagem mais citada nos documentos sendo abordada por 12 trabalhos. Essa interoperabilidade diminuiria o retrabalho no processo de representação descritiva, faria com que novos itens fossem disponibilizados mais rapidamente ao público ao diminuir o tempo empregado no tratamento desses itens e ainda garantiria representações mais consistentes e granulares.

Uma maior visibilidade dos recursos das bibliotecas no ambiente Web foi citada como vantagem por 6 documentos, essa vantagem seria importante pois as bibliotecas precisam ser relevantes na Web (onde atualmente se encontram a maioria dos usuários) e para isso 
dependem da visibilidade obtida através dos resultados dos buscadores, além disso, segundo Wenz (2013) coleções das bibliotecas que antes só seriam utilizadas por um público muito restrito estariam disponíveis para toda a comunidade.

Melhores resultados de busca foram citados por 8 documentos e prover a descoberta acidental de recursos por 6 documentos; com buscas mais intuitivas, os usuários poderiam saber por exemplo quais títulos relacionados existem em uma biblioteca, o melhor lugar para comprar esse item e serem direcionados para conteúdos que de alguma forma tem relação com o item de interesse, mesmo que esses conteúdos não estejam nos bancos de dados das bibliotecas (CATARINO; SOUZA, 2012). Localizar recursos relacionados a um período histórico ou relacionados a um local geográfico, localizar traduções, estudos e ensaios relacionados a uma determinada obra seriam exemplos de refinamento de busca que dados bibliográficos semânticos e interligados permitiriam aos usuários.

\subsection{Desafios relacionados à adequação de dados bibliográficos ao linked data}

Os desafios do processo de adequação os dados bibliográficos ao Linked Data foram estudados com o objetivo de verificar a viabilidade desse processo. Dentre os 56 artigos avaliados, 27 citaram um ou mais desafios relacionados à publicação e à adequação de dados bibliográficos ao Linked Data conforme apresentados no quadro 4 .

Quadro 4: Desafios relacionados à utilização de Linked Data para a publicação de dados bibliográficos.

\begin{tabular}{|c|c|c|}
\hline Autor(es) & Título & Desafios mencionados \\
\hline Long (2016) & $\begin{array}{l}\text { Disambiguating the Departed: } \\
\text { Using the Genealogist's Tools } \\
\text { to Uniquely Identify the Long } \\
\text { Dead and Little Known }\end{array}$ & $\begin{array}{l}\text { - Localizar dados que permitam identificar } \\
\text { de maneira única pessoas há muito tempo } \\
\text { falecidas ou desconhecidas. } \\
\text { - Evitar ambiguidade em registros ao } \\
\text { agrupar dados de autoridade de diversas } \\
\text { fontes. }\end{array}$ \\
\hline $\begin{array}{|ll|}\begin{array}{l}\text { Hickeye } \\
(2014)\end{array} & \text { Toves } \\
\end{array}$ & Managing Ambiguity In VIAF & $\begin{array}{l}\text { - Evitar ambiguidade em registros } \\
\text { centralizados de autoridade. }\end{array}$ \\
\hline $\begin{array}{l}\text { Leiva-Mederos et } \\
\text { al. (2013) }\end{array}$ & $\begin{array}{l}\text { AUTHORIS: a tool for authority } \\
\text { control in the semantic web }\end{array}$ & $\begin{array}{l}\text { - Diversos níveis de granularidade de dados } \\
\text { adotados pelas instituições ao longo do } \\
\text { mundo. } \\
\text { - A complexidade da conversão de dados } \\
\text { em MARC para RDF. } \\
\text { - Heterogeneidade dos dados gerados pela } \\
\text { Web. } \\
\text { - Lidar com as variações linguísticas será } \\
\text { trabalhoso. }\end{array}$ \\
\hline Malmsten (2013) & $\begin{array}{l}\text { Cataloguing in the Open - The } \\
\text { Disintegration and Distribution } \\
\text { of the Record }\end{array}$ & $\begin{array}{l}\text { - Realizar a distinção entre os dados internos } \\
\text { e externos. } \\
\text { - Confiar nos dados de fontes externas. } \\
\text { - Manter os dados permanentemente na } \\
\text { rede, pois se baixados tornam-se obsoletos. }\end{array}$ \\
\hline $\begin{array}{l}\text { Agenjo, Hernández } \\
\text { e Viedma (2012) }\end{array}$ & $\begin{array}{l}\text { Data Aggregation and } \\
\text { Dissemination of Authority } \\
\text { Records through Linked Open } \\
\text { Data in a European Context }\end{array}$ & $\begin{array}{l}\text { - Grande nível de inconsistência presente } \\
\text { nos links de fontes externas. } \\
\text { - Registrar os nomes geográficos e as } \\
\text { alterações desses ao longo dos anos. }\end{array}$ \\
\hline
\end{tabular}




\begin{tabular}{|c|c|c|}
\hline $\begin{array}{l}\text { Byrne e Goddard } \\
(2010)\end{array}$ & $\begin{array}{l}\text { The Strongest Link: Libraries } \\
\text { and Linked Data }\end{array}$ & $\begin{array}{l}\text { - O conceito de Linked Data ainda não é de } \\
\text { conhecimento de muitos bibliotecários. } \\
\text { - Dificuldade de confiar na segurança e na } \\
\text { garantia de segurança e privacidade de } \\
\text { dados. } \\
\text { - Relutância em adequar os dados por ser } \\
\text { uma mudança de grande magnitude. } \\
\text { - A existência de poucos dados interligados } \\
\text { faz com que não seja possível ver exemplos } \\
\text { práticos da funcionalidade de Linked Data. }\end{array}$ \\
\hline Han (2016) & $\begin{array}{l}\text { Establishing } \\
\text { and scalable workflows for } \\
\text { cataloging and metadata } \\
\text { services. }\end{array}$ & $\begin{array}{l}\text { - Preparar os profissionais para trabalhar } \\
\text { com novas tecnologias de informação, } \\
\text { garantir que estejam equipados, } \\
\text { possuam conhecimentos profissionais } \\
\text { interdisciplinares estejam abertos a } \\
\text { mudança. }\end{array}$ \\
\hline Bremer et al. (2016) & $\begin{array}{l}\text { Mining MARC's Hidden } \\
\text { Treasures: Initial Investigations } \\
\text { Into How Notes of the Past } \\
\text { Might Shape Our Future. }\end{array}$ & $\begin{array}{l}\text { - As notas são construídas de maneira pouco } \\
\text { padronizada dificultando a conversão das } \\
\text { mesmas. } \\
\text { - Variedade linguística dos dados, mesmo } \\
\text { em um único catálogo. }\end{array}$ \\
\hline $\begin{array}{l}\begin{array}{l}\text { Bidney } \\
(2013)\end{array} \\
\text { e } \quad \text { Clair }\end{array}$ & 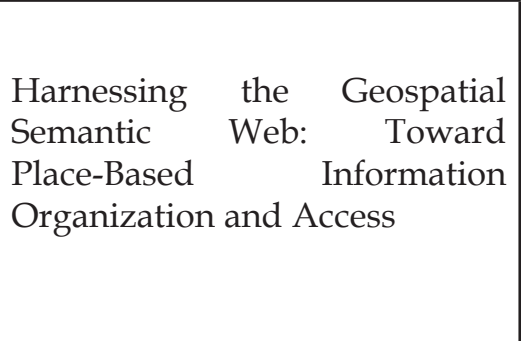 & $\begin{array}{l}\text { - As grandes alterações nas atividades do } \\
\text { profissional bibliotecário. } \\
\text { - Desenvolver um formato de metadados } \\
\text { moderno que seja aberto e flexível. } \\
\text { - Converter os dados em MARC para um } \\
\text { formato Linked Data. } \\
\text { - Falta de artigos publicados sobre Linked } \\
\text { Data. }\end{array}$ \\
\hline Laurence (2013) & $\begin{array}{l}\text { Linked Data and the Library of } \\
\text { Congress. }\end{array}$ & $\begin{array}{l}\text { - Necessidade de criação de milhões de } \\
\text { registros em RDF envolvendo tempo e } \\
\text { dedicação. } \\
\text { - Problemas de licenciamento podem } \\
\text { complicar o processo de disponibilização de } \\
\text { dados na World Wide Web. }\end{array}$ \\
\hline Talleras (2013) & $\begin{array}{l}\text { From Many Records to } \\
\text { One Graph: Heterogeneity } \\
\text { Conflicts in the Linked data } \\
\text { Restructuring Cycle. }\end{array}$ & $\begin{array}{l}\text { - Natureza heterogênea dos dados em } \\
\text { diversas fontes. } \\
\text { - Dificuldades na conversão do antigo } \\
\text { padrão (MARC) para um novo padrão. }\end{array}$ \\
\hline $\begin{array}{ll}\text { Richard } & \text { e } \\
\text { Thompson (2013) }\end{array}$ & $\begin{array}{l}\text { Moving Our Data to the } \\
\text { Semantic Web: Leveraging a } \\
\text { Content Management System } \\
\text { to Create the Linked Open } \\
\text { Library. }\end{array}$ & $\begin{array}{l}\text { - A prototipagem, revisão e experimentação } \\
\text { demanda tempo, mas é essencial para uma } \\
\text { mudança de grande magnitude. } \\
\text { - As ferramentas utilizadas no processo } \\
\text { precisam ser adequadas à realidade da } \\
\text { biblioteca. }\end{array}$ \\
\hline
\end{tabular}




\begin{tabular}{|c|c|c|}
\hline $\begin{array}{l}\text { Kumar, Ujjal e } \\
\text { Utpal (2013) }\end{array}$ & $\begin{array}{l}\text { Exposing MARC } 21 \text { Format for } \\
\text { Bibliographic Data As Linked } \\
\text { Data With Provenance. }\end{array}$ & $\begin{array}{l}\text { - Definir a procedência dos dados para } \\
\text { garantir a qualidade e a confiabilidade dos } \\
\text { mesmos. } \\
\text { - Demarcar as alterações dos dados em } \\
\text { tempo real (controle de versão). } \\
\text { - Converter os dados em formato MARC } \\
\text { para um formato Linked Data. }\end{array}$ \\
\hline $\begin{array}{l}\text { Perkins e Yoose } \\
(2013)\end{array}$ & $\begin{array}{l}\text { The Linked Open Data } \\
\text { Landscape in Libraries and } \\
\text { Beyond. }\end{array}$ & $\begin{array}{l}\text { - Pouco conhecimento da comunidade } \\
\text { acerca do que é Linked Data. } \\
\text { - Volume de dados em MARC a serem } \\
\text { convertidos. } \\
\text { - Tempo e recurso necessários para o } \\
\text { processo de conversão de dados. }\end{array}$ \\
\hline Mebmer (2013) & $\begin{array}{l}\text { Linking Library Metadata to the } \\
\text { Web: The German Experiences }\end{array}$ & $\begin{array}{l}\text { - Demanda por tempo e dinheiro para } \\
\text { realizar a conversão de dados e criação de } \\
\text { novos dados. }\end{array}$ \\
\hline Solodovnik (2013) & $\begin{array}{l}\text { Bibliographic Data Towards the } \\
\text { Semantic Web: A Review of Key } \\
\text { Issues and Recent Experiences. }\end{array}$ & $\begin{array}{l}\text { - Disponibilizar grandes quantidades de } \\
\text { dados nos formatos necessários. } \\
\text { - Definir quais dados serão interligados com } \\
\text { fontes externas. } \\
\text { - Relutância da comunidade } \\
\text { biblioteconômica em utilizar os princípios } \\
\text { do Linked Data. } \\
\text { - Falta de profissionais com conhecimentos } \\
\text { e aptidões necessárias para aplicar os } \\
\text { princípios de Linked Data na implementação } \\
\text { e manutenção de novos catálogos. }\end{array}$ \\
\hline Frederick (2016) & $\begin{array}{l}\text { Metadata specialists in } \\
\text { transition: from MARC } \\
\text { cataloging to linked data } \\
\text { and BIBFRAME (data deluge } \\
\text { column). }\end{array}$ & $\begin{array}{l}\text { - Os catalogadores possuem pouco tempo } \\
\text { para testar novos métodos. } \\
\text { - As bibliotecas oferecem pouco incentivo } \\
\text { para que testes com novas tecnologias } \\
\text { aconteçam. }\end{array}$ \\
\hline $\begin{array}{l}\text { F u k u y a m a, } \\
\text { Hashizume, } \\
\text { e Nagai (2015) }\end{array}$ & $\begin{array}{l}\text { Use and Connect: Linked Open } \\
\text { Data of National Diet Library, } \\
\text { Japan. }\end{array}$ & $\begin{array}{l}\text { - Lidar com a ambiguidade de dados } \\
\text { agrupados de diversas fontes. }\end{array}$ \\
\hline $\begin{array}{l}\text { Goddard e Seeman } \\
\text { (2015) }\end{array}$ & $\begin{array}{l}\text { Preparing the Way: Creating } \\
\text { Future Compatible Cataloging } \\
\text { Data in a Transitional } \\
\text { Environment }\end{array}$ & $\begin{array}{l}\text { - Converter os dados do formato MARC } \\
\text { para RDF automaticamente com qualidade. }\end{array}$ \\
\hline $\begin{array}{l}\text { Fallgren et al. } \\
(2014)\end{array}$ & $\begin{array}{l}\text { The Missing Link - The } \\
\text { Evolving Current State of } \\
\text { Linked Data for Serials. }\end{array}$ & $\begin{array}{l}\text { - Necessidade de substituir o MARC como } \\
\text { formato para descrição. }\end{array}$ \\
\hline Steen (2014) & $\begin{array}{l}\text { Linked data as a tool for } \\
\text { attractive user services }\end{array}$ & $\begin{array}{l}\text { - Apresentar uma interface amigável ao } \\
\text { usuário. }\end{array}$ \\
\hline
\end{tabular}




\begin{tabular}{|c|c|c|}
\hline Wenz (2013) & $\begin{array}{l}\text { Linked Open Data for New } \\
\text { Library Services: The Example } \\
\text { of data.bnf.fr. }\end{array}$ & $\begin{array}{l}\text { - Lidar com os dados duplicados. } \\
\text { - Lidar com a consistência e a granularidade } \\
\text { irregular dos dados. }\end{array}$ \\
\hline Alemu et al. (2012) & $\begin{array}{l}\text { Linked Data for libraries: } \\
\text { Benefits of a conceptual shift } \\
\text { from library-specific record } \\
\text { structures to RDF-based data } \\
\text { models. }\end{array}$ & $\begin{array}{l}\text { - Grande quantidade de dados em MARC } \\
\text { e a dificuldade de convertê-los para outros } \\
\text { formatos. } \\
\text { - Tentativas se focam nos dados legados } \\
\text { e ignoram abordagens de metadados } \\
\text { construídas socialmente (orientadas pelo } \\
\text { usuário). } \\
\text { - Reconceitualizar RDA e FRBR para que } \\
\text { esses atendam a demanda do Linked Data. }\end{array}$ \\
\hline Johnson (2013) & $\begin{array}{l}\text { Indexing Linked Bibliographic } \\
\text { Data with JSON-LD, BibJSON } \\
\text { and Elasticsearch. }\end{array}$ & $\begin{array}{l}\text { - O impacto de trabalhar como uma massa } \\
\text { caótica de dados sobre a atuação do } \\
\text { bibliotecário. } \\
\text { - Lidar com heterogeneidade do ambiente } \\
\text { Web. }\end{array}$ \\
\hline $\begin{array}{l}\text { Lampert, } \\
\text { Southwick } \\
\text { Southwick (2015) }\end{array}$ & $\begin{array}{l}\text { Preparing Controlled } \\
\text { Vocabularies for Linked Data: } \\
\text { Benefits and Challenges. }\end{array}$ & $\begin{array}{l}\text { - Expandir do conhecimento dos } \\
\text { profissionais, que teriam que adquirir } \\
\text { conhecimentos interdisciplinares. } \\
\text { - Obter um equilíbrio entre padronização e } \\
\text { riqueza para criar um ambiente de dados } \\
\text { verdadeiramente global. } \\
\text { - Confiar nos dados de fontes externas. }\end{array}$ \\
\hline Carpenter (2013) & \begin{tabular}{|l} 
Preparing Controlled \\
Vocabularies for Linked Data: \\
Benefits and Challenges.
\end{tabular} & $\begin{array}{l}\text { - O grande número de recursos necessários } \\
\text { para adequação dos dados bibliográficos. }\end{array}$ \\
\hline $\begin{array}{l}\text { Catarino e Souza } \\
(2012)\end{array}$ & $\begin{array}{l}\text { A representação descritiva no } \\
\text { contexto da web semântica. }\end{array}$ & $\begin{array}{l}\text { - Introduzir um identificador único para } \\
\text { cada recurso descrito seria trabalhoso e } \\
\text { custoso. }\end{array}$ \\
\hline
\end{tabular}

Fonte: Autores (2017)

Dois desafios se destacaram entre os resultados, a heterogeneidade dos dados disponibilizados na Web e a conversão do grande volume de dados descritos em MARC21 a um formato compatível com o Linked Data.

A questão da heterogeneidade dos dados presentes no ambiente Web está relacionada ao fato de que não existem padrões de descrição amplamente adotados nesse ambiente, fazendo com que a verificação da veracidade e da qualidade dos dados seja complexa. Esse desafio cria certa resistência das bibliotecas em confiar nos dados advindos de fontes externas. Para lidar com esse desafio seria necessário desenvolver métodos para identificar permanentemente dados de fontes externas e também definir quais dados e de quais fontes seriam reaproveitados. Em relação à qualidade e veracidade dos dados alojados na Web, a ampla utilização do RDF deve, a partir do uso de ontologias e vocabulários, tornar mais viável a verificação desses dados.

O segundo desafio, converter o grande volume de dados descritos em MARC21 para o formato proposto pelo Linked Data (RDF) é agravado pelo fato de que a prototipagem é uma etapa importante do processo de conversão de dados de um formato para outro (RICHARD; THOMPSON, 2013); essa prototipagem envolve a necessidade de recursos financeiros e de mão de obra especializada, porém, os catalogadores normalmente possuem pouco tempo e incentivo para realizar testes e investir em novas tecnologias (FREDERICK, 2016). Muitos itens aguardam tratamento nas bibliotecas e o processo de conversão para um novo formato inicialmente agravaria essa situação. Para superar esse desafio 
seria necessário demonstrar efetivamente aos gestores de bibliotecas as vantagens do processo, porém, como afirmam Byrne e Goddard (2010) a existência de poucos dados interligados faz com que não seja possível ver exemplos práticos da funcionalidade do Linked Data.

Outro agravante é o fato de que mesmo nos catálogos de bibliotecas, a qualidade e a granularidade dos dados são irregulares (WENZ, 2013), isso tornaria complexa a criação de ferramentas que permitam a conversão automatizada de grandes quantidades de dados descritos utilizando o formato MARC21 para o novo formato.

\section{CONSIDERAÇÕES FINAIS}

Esta pesquisa foi pautada na Revisão Sistemática da Literatura, um método de coleta de dados pouco utilizado no campo da Ciência da Informação que permite a realização de uma pesquisa estruturada e metódica, que resulta em dados consistentes e auditáveis.

A utilização deste método permitiu criar uma visão geral de como tem sido discutida a relação entre o movimento Linked Data e os dados bibliográficos, a partir do estudo do enfoque dos documentos contidos nas principais bases de dados da Ciência da Informação. Concluiu-se que existe uma grande preocupação da comunidade biblioteconômica em publicar os trabalhos de adequação de dados feitos em suas bibliotecas, em registrar as etapas deste processo, os desafios enfrentados e as vantagens advindas dessa adequação. Essa preocupação é direcionada ainda para a questão dos dados de autoridade, pois esses possuem um alto potencial de ligações e seriam uma das chaves para a adequação dos dados bibliográficos ao Linked Data.

Notou-se ainda uma preocupação com a conversão da grande quantidade de dados construídos no formato MARC21 para um novo formato compatível com o movimento Linked Data, já que seria inviável desconsiderar todo o tempo, trabalho e recursos gastos com a descrição realizada utilizando esse formato, principalmente considerando que algumas bibliotecas ainda enfrentam dificuldades em realizar a conversão retrospectiva de seus dados.

Essa preocupação é reafirmada nos resultados, dos desafios relacionados à adequação dos dados bibliográficos ao Linked Data, onde destacaram-se dois desafios: a supracitada preocupação com a conversão dos dados registrados em formato MARC21 e a heterogeneidade dos dados publicados no ambiente Web, que intimida iniciativas de adequação pela preocupação com as dificuldades em garantir a qualidade e a confiabilidade desses dados.

Foram apresentadas diversas vantagens de se adequar os dados bibliográficos ao Linked Data, dentre elas destacaram-se a interoperabilidade dos dados com fontes externas ao catálogo bibliográfico (permitida pela utilização do $R D F$ ), melhores resultados de busca, maior visibilidade dos dados bibliográficos na Web e, ainda, a descoberta acidental de recursos. Essas vantagens permitiram agilizar o processo de catalogação descritiva nas bibliotecas, possibilitando aos bibliotecários empregar mais tempo na descrição e gerar dados mais consistentes e granulares, já que um item precisaria ser descrito uma única vez, apenas no país de origem e que essa descrição precisaria apenas ser completada (ou enriquecida) com os dados locais. Além disso, tornariam os catálogos mais intuitivos e atrativos aos usuários.

Comparados os desafios e as vantagens relacionados à aplicação dos princípios do Linked Data para a elaboração e a publicação de dados bibliográficos, conclui-se que as vantagens apresentadas tornam relevante o emprego de esforços para superar esses desafios. Concluise também que é viável superar os desafios mencionados, ainda que esforços coletivos da comunidade biblioteconômica precisem ser empregados nesse sentido. Espera-se que, em futuro próximo, esses desafios sejam superados e que as bibliotecas possam se beneficiar amplamente das funcionalidades do ambiente Web. 
Artigo recebido em 16/02/20I8 e aceito para publicação em 05/04/2018

\title{
ADAPTING BIBLIOGRAPHIC DATA TO LINKED DATA: requirements, advantages and challenges
}

\begin{abstract}
Linked Data was developed in order to meet the current technological context and can potentially be applied to the bibliographic domain. The objective was to verify the feasibility and relevance of matching the bibliographic data to the principles of Linked Data. The data collection was based on a qualitative-quantitative methodology, based on the accomplishment of a Systematic Review of Literature. The data were analyzed in the light of the following categories: document focus, requirements for the adequacy of bibliographic data to Linked Data, advantages and challenges related to this adequacy. As a result, the Resource Description Framework (RDF) and the Uniform Resource Identifier (URI) were identified as necessary requirements to provide bibliographic data adequacy to Linked Data. The main advantages identified were data interoperability, better search results, greater visibility of library data in the Web environment and promotion of accidental discovery of resources. The main challenges identified were the heterogeneity of the data available on the Web and the conversion of the data described in MARC2I format. It was concluded that bibliographic data can be adapted to Linked Data, however, many challenges still need to be overcome to allow this reality.
\end{abstract}

Keywords: $\quad$ Bibliographic catalogs. Linked Data. Systematic Review of Literature.

\section{REFERÊNCIAS}

AGENJO, X.; HERNÁNDEZ, F.; VIEDMA, A. Data aggregation and dissemination of authority records through linked open data in a european context. Cataloging \& Classification Quarterly, [S.L.], v. 50, n. 8, p.803-829, nov. 2012. Disponível em: <http://www.tandfonline. com/doi/ abs/10.1080/01639374.2012.711441? journalCode=wccq20 $>$. Acesso em: 28 nov. 2017.

ALEMU, G. et al. Linked data for libraries. New Library World, [S.L.], v. 113, n. 11-12, p.549570, nov. 2012. Disponível em: <http://www. emeraldinsight.com/doi/full/10.1108/030748012 11282920>. Acesso em: 28 nov. 2017.

ALMEIDA, M. B.; BARACHO, R. M. A.; SOUZA, R. R. Ciência da informação em transformação: big data, nuvens, redes sociais e web semântica. Ci. Inf., Brasília, DF, v. 42 n. 2, p.159-173, maioago. 2013. Disponível em: <http://revista.ibict. br/ciinf/article/view/1379>. Acesso em: $01 \mathrm{dez}$. 2016.
ARAKAKI, F. A. Linked data: ligação de dados bibliográficos. 2016. 144 f. Dissertação (Mestrado em Ciência da Informação) Faculdade de Filosofia e Ciências, Universidade Estadual Paulista, Marília, 2016. Disponível em: <http:/ / repositorio.unesp.br/bitstream/ handle/11449/147979/arakaki_fa_me_mar. pdf? sequence $=2 \&$ isAllowed $=y>$. Acesso em: 17 jul. 2017.

ASSUMPÇÃO, F. S.; SANTOS, P. L. V. A. C. A importância do controle de autoridade: uma abordagem baseada nos objetivos e nas funções dos catálogos. In: ENCONTRO NACIONAL DE CATALOGADORES,1., 2012, Rio de Janeiro. Anais...Rio de Janeiro: Biblioteca Nacional, 2012. 1-15. Disponível em: < http:/ / eprints.rclis. org/18843/1/assumpcao-santos-a-importanciado-controle-de-autoridade.pdf $>$. Acesso em: 17 jul. 2017.

BERNERS-LEE, T. Linked data, 2006. Disponível em: <https://www.w3.org/DesignIssues/ LinkedData.html>. Acesso em: 17 jul. 2017. 
BIDNEY, M.; CLAIR, K. Harnessing the geospatial semantic web: toward place-based information organization and access. Cataloging \& Classification Quarterly, [S.L.], v. 52, n. 1, p.6976, dez. 2013. Disponível em: <http://www. tandfonline.com/doi/pdf/10.1080/01639374.201 3.852038>. Acesso em: 28 nov. 2017.

BYRNE, G.; GODDARD, L. The strongest link: libraries and linked data. D-lib Magazine, [S.L.], v. 16, n. 11-12, [N.P.], nov. 2010. Disponível em: <http:/ / www.dlib.org/dlib/november10/ byrne/11byrne.html>. Acesso em: 28 nov. 2017.

BORIE, J.; VAN BALLEGOOIE, M. From recordbound to boundless: FRBR, linked data, and new possibilities for serials cataloging. The Serials Librarian, [S.L.], v. 66, n. 1-4, p.76-87, maio 2014. Disponível em: <http://www.tandfonline.com/ doi/full/10.1080/0361526X.2014.879527>. Acesso em: 28 nov. 2017.

CARPENTER, T. A. Drafting a Road Map for the Bibliographic Future. Library and Information Science Magazines, [S.L], v. 33, n. 3, [N.P], abr. 2013. Disponível em: <https://www.questia. com/read/1G1-324982796/drafting-a-road-mapfor-the-bibliographic-future>. Acesso em: 28 nov. 2017.

CARRAGÁIN, E. N. Ó. et al. Linked data authority records for Irish place names. International Journal On Digital Libraries, [S.L], v. 15, n. 2-4, p.74-85, out. 2014. Disponível em: <https://link.springer.com/ article/10.1007/s00799-014-0129-8>. Acesso em: 28 nov. 2017

CATARINO, M. E.; SOUZA, T. B. A representação descritiva no contexto da web semântica. TransInformação, Campinas, v. 2, n. 24, p. 77-90, maio-ago., 2012. Disponível em: $<$ http:// periodicos.puccampinas.edu.br/seer/ index.php/transinfo/article/view/766/746>. Acesso em: 17 jul. 2017.
CLAYPHAN, R.; HASLHOFER, B; ISAAC, A. Europeana: moving to linked open data. Isq, [S.L.], v. 24, n. 2, p.34-40, ago. 2012. Disponível em: <http://www.niso.org/apps/ group_public/download.php/9407/IP_Isaacetal_Europeana_isqv24no2-3.pdf $>$. Acesso em: 28 nov. 2017.

COYLE, K. Designing data for use: from alphabetic order to linked data. Serials, [S.L.], v. 24, n. 2, p.154-159, jul. 2011. Disponível em: $\quad<$ https://serials.uksg.org/ articles/10.1629/24154/>. Acesso em: 28 nov. 2017.

FREDERICK, D. E. Metadata specialists in transition: from MARC cataloging to linked data and BIBFRAME. Library Hi Tech News, [S.L.], v. 33, n. 4, p.1-5, jun. 2016. Disponível em: <http:// www.emeraldinsight.com/doi/full/10.1108/ LHTN-03-2016-0015>. Acesso em: 28 nov. 2017.

FREITAS JUNIOR, N.; JACYNTO, M. D. A. Um protótipo linked data para catalogação semântica de publicações. Perspectivas em Ciência da Informação, Minas Gerais, v. 21, n. 4, p.1-18, out.-dez. 2016. Disponível em <http:// portaldeperiodicos.eci.ufmg.br/index.php/pci/ article/view/2664/1798> . Acesso em: 17 jul. 2016.

FUKUYAMA, J.; HASHIZUME, A.; NAGAI, Y. Use and connect: linked open data of the National Diet Library, Japan. In: INTERNATIONAL CONFERENCE ON DUBLIN CORE AND METADATA APPLICATIONS, 2015, São Paulo. Anais...São Paulo: Dublin Core Metadata Initiative, 2015. 1-4. Disponível em: < http:// www.ndl.go.jp/jp/aboutus/cooperation/ news/2015/dc2015.pdf> . Acesso em: 17 jul. 2017.

GODBY, C. J.; SMITH-YOSHIMURA, K. From records to things: managing the transition from legacy library metadata to linked data. Bulletin Of The Association For Information Science And Technology, [S.L.], v. 43, n. 2, p.18-23, dez. 
2016. Disponível em: <http://onlinelibrary. wiley.com/doi/10.1002/bul2.2017. 1720430209/ abstract>. Acesso em: 28 nov. 2017.

GODDARD, L.; SEEMAN, D. Preparing the way: creating future compatible cataloging data in a transitional environment. Cataloging \& Classification Quarterly, [S.L.], v. 53, n. 3-4, p.331-340, dez. 2014. Informa UK Limited. Disponível em: <http://www. tandfonline.com/doi/abs/10.1080/01639374. 2014.946573? journalCode $=$ wccq20 $>$. Acesso em: 28 nov. 2017

GONZALES, B. M. Linking libraries to the web: linked data and the future of the bibliographic record. Information Technology And Libraries, [S.L.], v. 33, n. 4, p.10-22, dez. 2014. Disponível em: <https://ejournals.bc.edu/ojs/ index.php/ital/article/view/5631>. Acesso em: 28 nov. 2017.

HAN, M. K. Establishing sustainable and scalable workflows for cataloging and metadata services. Library Management, [S.L.], v. 37, n. 6-7, p.308-316, ago. 2016. Disponível em: <http:// Www.emeraldinsight.com/doi/full/10.1108/ LM-04-2016-0031>. Acesso em: 28 nov. 2017.

HICKEY, T. B.; TOVES, J. A. Managing ambiguity in VIAF. D-lib Magazine, [S. L.], v. 20, n. 7-8, [N.P.], ago. 2014. Disponível em: <http://www. dlib.org/dlib/july14/hickey/07hickey.html>. Acesso em: 28 nov. 2017.

JOHNSON, T. Indexing Linked Bibliographic Data with JSON-LD, BibJSON and Elasticsearch. The Code4lib Journal, [S.L.], v. 19, n. 1, [N.P], jan. 2013. Disponível em: <http:// journal.code4lib.org/articles/7949>. Acesso em: 28 nov. 2017.

KUMAR, S.; UJJAL, M.; UTPAL, B. Exposing MARC 21 format for bibliographic data as linked data with provenance. Journal Of Library Metadata, [S.1.], v. 13, n. 2-3, p.212-229, jul. 2013. Disponível em: < http://www.tandfonline.com/ doi/abs/10.1080/19386389.2013.826076>. Acesso em: 28 nov. 2017.

LAMPERT, C. K.; SOUTHWICK, R.; SOUTHWICK, S. B. Preparing controlled vocabularies for linked data: benefits and challenges. Journal Of Library Metadata, [S.L.], v. 15, n. 3-4, p.177-190, out. 2015. Disponível em: <http://www. tandfonline.com/doi/abs/10.1080/19386389. 2015.1099983? journalCode=wjlm20>. Acesso em: 28 nov. 2017.

LAURENCE, C. M. Linked data and the Library of Congress. Library Philosophy And Practice, Nebraska, p.224, set. 13. Disponível em: <http:// digitalcommons.unl.edu/libphilprac/?utm source $=$ digitalcom mons.unl.edu/ libphilprac/1114\&utm_medium =PDF\&utm_ campaign=PDFCoverPages $>$. Acesso em: 28 nov. 2017.

LEIVA-MEDEROS, A. et al. Authoris: a tool for authority control in the semantic web. Library Hi Tech, [S.L.], v. 31, n. 3, p. 536-553, 2013. Disponível em: <http://www.emeraldinsight. com/doi/pdfplus/10.1108/LHT-12-20112-0135> . Acesso em: 17 jul. 2017.

LONG, C. E. Disambiguating the departed: using the genealogist's tools to uniquely identify the long dead and little known. Library Resources \& Technical Services, [S.L.], v. 60, n. 4, p.236-247, out. 2016. Disponível em: <https://journals.ala. org/index.php/lrts/article/view/6135/7919 >. Acesso em: 28 nov. 2017.

MALMSTEN, Martin et al. Cataloguing in the open - the disintegration and distribution of the record. Jlis.it, Csia, v. 4, n. 1, p.418-423, jan. 2013. Disponível em: <https://www.jlis.it/article/ view/5512/7921>. Acesso em: 28 nov. 2017.

MANCINI, M. C.; SAMPAIO, R. F. Estudos de revisão sistemática: um guia para síntese criteriosa da evidência científica. Rev. bras. 
fisioter., São Carlos, v. 11, n. 1, p. 83-89, fev. 2007. Disponível em: <http://www.scielo. br $/$ scielo.php? script $=$ sci_arttext\&pid $=S 1413$ -

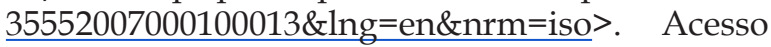
em: 17 jul. 2017.

MARCONDES, C. H. Linked data: dados interligados, interoperabilidade entre arquivos, bibliotecas e museus na web. Encontros Bibli., Florianópolis, v. 17, n. 34, p.171-192, maio-ago. 2012. Disponível em: Acesso em: 03 dez. 2016.

MARTINI, P. Bibliographic standards and linked data: towards a collaboration between cultural and commercial sectors. Jlis.it, Csia, v. 4, n. 1, p.306-311, jan. 2013. Disponível em: <https:// www.jlis.it/ article/viewFile/6315/7911>. Acesso em: 28 nov. 2017.

MEBMER, G. Linking library metadata to the web: the german experiences. Jlis.it, Csia, v. 4, n. 1, p.392-401, jan. 2013. Disponível em: <https:// www.jlis.it/article/view/5507/7878>. Acesso em: 28 nov. 2017.

MEY, E. S. A.; SILVEIRA, N. C. Catalogação no plural. Brasília, DF: Briquet de Lemos, 2009. 217 p.

MILLER, E.; OGBUJI, U. Linked data design for the visible library. Bulletin Of The Association For Information Science And Technology, [S.L.], v. 41, n. 4, p.23-29, maio 2015. Disponível em: <http://onlinelibrary.wiley.com/doi/10.1002/ bult.2015.1720410409/pdf>. Acesso em: 28 nov. 2017.

PERKINS, J.; YOOSE, B. The linked open data landscape in libraries and beyond. Journal of Library Metadata, [S.L.], v. 13, n. 2-3, p.197211, jul. 2013. Disponível em: <http://www. tandfonline.com/doi/full/10.1080/19386389.201 3.826075>. Acesso em: 28 nov. 2017.

RAMALHO, R. A. S. Web Semântica: aspectos interdisciplinares da gestão de recursos informacionais no âmbito da Ciência da Informação. 2006. 120 f. Dissertação (Mestrado em Ciência da Informação) - Faculdade de Filosofia e Ciências, Universidade Estadual Paulista "Júlio de Mesquita Filho", Marília, 2006.

SANTARÉM SEGUNDO, J. E.; SERRA, L. G. O catálogo da biblioteca e o linked data. Em Questão, Porto Alegre, v. 23, n. 2, p. 167-185, maio-ago. 2017. Disponível em:<http://seer. ufrgs.br/index.php/EmQuestao/article/ view/67162>. Acesso em: 17 jul. 2017.

SANTOS NETO, A. L. et al. Tecnologias de dados abertos para interligar bibliotecas, arquivos e museus: um caso machadiano. TransInformação, Campinas, v. 25, n. 1, p. 81-87, jan.-abr., 2013. Disponível em: <http://www.scielo.br/pdf/ tinf/v25n1/a08v25n1.pdf>. Acesso em: 17 jul. 2017.

SEPPÄLÄ, Marja-liisa. Toward multidimensional descriptions. Scandinavian Library Quarterly, [S.L.], [N.P.], mar. 2014. Disponível em: $\quad<$ http:/ / slq.nu/?article=volume-47no-3-2014-12>. Acesso em: 28 nov. 2017.

SOLODOVNIK, I. Bibliographic data towards the semantic web: a review of key Issues and recent experiences. Bilgi Dunyas, [S.L.], v. 1, n. 13, p.1756, jan. 2013. Disponível em: < http://www. oalib.com/paper/2086352 >. Acesso em: 28 nov. 2017

STEEN, Siren. Linked data as a tool for attractive user services: report on a complex, ongoing project. Scandinavian Library Quarterly, [S.L.], v. 43, n. 3, [N.P.], jan. 2014. Disponível em: <http:/ / slq.nu/ ?article $=$ volume-47-no-3-2014-5>. Acesso em: 28 nov. 2017.

TALLERAS, K. From many records to one graph: heterogeneity conflicts in the linked data restructuring cycle. Ir information research, Copenhagen, v. 18, n. 3, [N.P.], ago. 2013. Disponível em: <http://www. 
informationr.net/ir/18-3/colis/paperC18.html\#. Wg2onFtSzGg>. Acesso em: 28 nov. 2017.

RICHARD, J; THOMPSON, K. Moving our data to the semantic web: leveraging a content management system to create the linked open library. Journal Of Library Metadata, [S.L.], v. 13, n. 2-3, p.290-309, jul. 2013. Disponível em: <http://www.tandfonline.com/doi/abs/10.10 80/19386389.2013.828551>. Acesso em: 28 nov. 2017.
WENZ, R. Towards a web of data: applications and experiences. Jilis.it, Csia, v. 4, n. 1, p.404-413, jan. 2013. Disponível em: <https://www.jlis.it/ article/view/5509/7919>. Acesso em: 28 nov. 2017.

$\mathrm{XU}$, A. et al. Initial BIBFRAME 2.0 modeling for the library information spotlight "Opera Planet". Journal Of Library Metadata, [S.L.], v. 16, n. 3-4, p.202-227, out. 2016. Disponível em: <http://www.tandfonline.com/doi/full/10.10 80/19386389.2016.1258910>. Acesso em: 28 nov. 2017. 